\title{
Use of Withania somnifera root powder for production of monosex Nile tilapia, Oreochromis niloticus
}

\author{
Manojit De ${ }^{1}$, Suman Bhusan Chakraborty ${ }^{1}$ \\ ${ }^{1}$ Fish Endocrinology Research Unit, Department of Zoology, University of Calcutta, India
}

\begin{abstract}
Three days old mixed sex juveniles of Nile tilapia (mean weight $0.025 \pm 0.009 \mathrm{~g}$; mean length $1.25 \pm$ $0.012 \mathrm{~cm}$ ) were fed diets containing root powder of Withania somnifera at the concentrations of 0.0, 2.0, 3.0, 3.5, 5.0, 6.5, 7.0, 8.0 and $9.5 \mathrm{~g} / \mathrm{kg}$ feed for 30 days. Dietary treatment with powdered W. somnifera roots at different concentrations except $8.0 \mathrm{~g} / \mathrm{kg}$ and $9.5 \mathrm{~g} / \mathrm{kg}$ showed no significant difference $(P>0.05)$ in survival percentage compared to that in control group. Dietary treatment with $W$. somnifera root powder caused significant increase $(P<0.05)$ in percentage of males compared to that in untreated control. The highest percentage of males $(93.73 \pm 4.2)$ was observed in $9.5 \mathrm{~g} / \mathrm{kg}$ group, but it showed significantly lower $(P<0.05)$ survival percentage (56.67 \pm 3.0$)$ compared to other treatment categories. Fish fed diets containing W. somnifera root powder at the concentration of $6.5 \mathrm{~g} / \mathrm{kg}$ feed showed high percentage of survival (97.50 \pm 1.4$)$ and male (91.43 \pm 0.9$)$, and hence might be considered the best treatment regime. The plant material is reported to show presence of phytochemicals such as tannins, saponins, steroids, terpenoids and flavonoids, which might be associated with its androgenic property.
\end{abstract}

Keywords: Orochromis niloticus, Phytochemicals, Root powder, Sex reversal, Withania somnifera

\section{Introduction}

Nile tilapia, Oreochromis niloticus (Linnaeus, 1758) is widely cultured in many tropical and subtropical countries of the world [1,2]. Due to their faster growth rate, tolerance to harsh environmental conditions and easy culture technique, tilapia offers possible commercial protein sources [3, 4]. The fish is reported to sexually mature at a young age of around 3 months [5] which leads to uncontrolled breeding of tilapia in ponds resulting in excessive recruitment, stunting and a low percentage of marketable-sized fish. Hormone treatment developed to combat this challenge does not change the genotype of the fish but affects the expression of the phenotype. Production of all male population through administration of androgen (17- $\alpha$ methyl testosterone) is considered to be the most effective and economically feasible method for obtaining all male tilapia populations [6]. However, widespread use of large quantities of such synthetic steroid hormones might have a residual effect and pose a health risk to human [7]. These compounds including their metabolites may interfere with the normal endocrine homeostasis at a very low concentration. The presence of testosterone and its metabolite androstenedione in the aquatic ecosystem was linked to the undesirable masculinisation of female mosquito fish [8]. Because of such potential ecological and health-related hazards of these synthetic steroids, the use of plant materials is a potential alternative to be explored [9].

It has been reported that phytochemicals have various biological attributes like appetite enhancer, growth promoter, stress reducer, antimicrobial, tonic and immunostimulator, which are useful in fish culture [10, 11]. It is anticipated that phytochemicals such as alkaloids, flavonoids, steroids, terpenoids, etc. which are natural steroid-like compounds, may act as endocrine modulators and either block de novo synthesis of estrogen by their aromatase inhibitor capacity or exhibit antagonist activity to nuclear estrogen receptors in primordial gonadal cells, among other unidentified mechanisms $[12,13]$. If such activity is precisely expressed by these chemicals, they could provide an alternative to synthetic inhibitors to induce changes in the phenotypic process of sex differentiation in fish gonads. Natural plant chemicals with expected safer utilization and handling issues, and possibly lower toxicity for both fish and the surrounding environment, are a very attractive alternative to synthetic steroids for induction of sex reversal in fish [14]. However, all the phytochemicals may not be equally potent in virilization of fish and a clear documentation needs to be conducted to establish the efficacy of phytochemicals in producing all-male fish population. Withania somnifera (L) Dunal, commonly known as Asgandh or Ashvaganadha, a xerophytic plant belonging to family Solanaceae, is one of the most potent aphrodisiacs used in traditional systems of medicine like Unani and Ayurveda for human use. Roots and leaves of this plant are used for medicinal purposes. Its aphrodisiac properties have been proved effective in improving semen quality as well as in development of testicles in mammalian model system [15, 16]. It is reported to improve blood circulation throughout the body and enhances sperm quality. It is also found to protect from neurodegenerative disorders like Parkinson's disease [17] and reduces the occurrence of various health disorders [18]. However, there has been no report regarding its effect on sex reversal of fish. 
Considering these aspects, the major objective of the present work was to investigate the potential effect of W. somnifera root on masculinisation of Nile tilapia, and to determine an ideal concentration for dietary administration of the root powder that might produce maximum percentage of males in Nile Tilapia population.

\subsection{Collection of fish seed}

\section{Materials and methods}

Newly hatched juveniles of mixed-sex Nile tilapia, Oreochromis niloticus (Linnaeus) were collected from the Hatchery of Government of West Bengal, oxygen-packed and transported to the laboratory.

\subsection{Dietary treatment of fish with powdered plant material}

W. somnifera roots were procured from the local plant market, washed in sterile distilled water, air-dried in shade and ground powdered.

Three days old mixed sex juveniles of Nile tilapia (mean weight $0.025 \pm 0.009 \mathrm{~g}$; mean length $1.25 \pm$ $0.012 \mathrm{~cm}$ ) were randomly allocated into 9 groups (40 fish / group). Eight groups were fed diets containing powdered W. somnifera roots at concentrations of 2.0, 3.0, 3.5, 5.0, 6.5, 7.0, 8.0 and $9.5 \mathrm{~g} / \mathrm{kg}$ feed, one group was fed control diet without plant powder. The powdered plant materials were mixed thoroughly with the finely ground $(<500-1000 \mu \mathrm{m})$ artificial diet containing $30 \%$ crude protein (Tokyo, Japan). It was then wetted with deionized water, mixed thoroughly, formed with a pelleter (diameter $2 \mathrm{~mm}$ ), and dried at room temperature. Pelleted feed was pulverized before feeding to the juvenile fish. The experiment was conducted for 30 days and the fish were fed with respective diets at a rate of $20 \%$ body weight / day. The aquaria were continuously aerated and maintained in heated $\left(\mathrm{T}=27 \pm 2^{\circ} \mathrm{C}\right)$ static systems. Water in all aquaria was replaced manually and the fish was kept under similar photoperiod (14 L: $10 \mathrm{D})$. This entire experimental set up was conducted simultaneously in triplicate.

\subsection{Sexing of fish}

Sexing of the juvenile fish was done by the standard acetocarmine squash technique of gonads [19]. Histological studies of the gonads were also performed.

\subsection{Statistical analysis}

All data are expressed in terms of mean \pm standard error (SE). Treatment effects on different parameters were analyzed by one-way analysis of variance (ANOVA) after checking normality by Shapiro-Wilk's test. Where significant differences were found, a Tukey's test was performed for separating treatment means. All statistical analysis was performed using the SPSS version 11.5 for Windows.

\section{Results and Discussion}

The control group of fish fed diets without plant powder showed a high survival percentage of $98.33 \pm 0.8 \%$. Dietary treatment with powdered W. somnifera roots at different concentrations except $8.0 \mathrm{~g} / \mathrm{kg}$ and $9.5 \mathrm{~g} / \mathrm{kg}$ showed no significant difference $(\mathrm{P}>0.05)$ in survival percentage compared to that in control group (Table 1). However, treatment with powdered W. somnifera roots at the concentration of $8.0 \mathrm{~g} / \mathrm{kg}$ and $9.5 \mathrm{~g} / \mathrm{kg}$ showed very low survival percentage, which was significantly lower $(\mathrm{P}<0.05)$ compared to other treatment categories including the control (Table 1). These results indicate that dietary treatment with $W$. somnifera root powder at concentrations upto $7.0 \mathrm{~g} / \mathrm{kg}$ have no adverse effect on general fish health. But addition of a high concentration of the root powder in fish feed may cause high mortality. Withania roots were reported to contain tannin [20], which is known to be bitter and form high polyphenol complex with protein thereby making it unavailable in the diet. Tannin may decrease protein quality by decreasing digestibility and palatability. It is also known to inhibit the activities of digestive enzymes [21]. The presence of tannin in high proportion in diets fortified with higher concentrations of the root powder might have resulted in poor food consumption by fish leading to high percentage of mortality.

Fish fed diets containing plant material at any concentration showed significantly higher $(p<0.05)$ percentage of males than the control group (Table 1). The highest percentage of males (93.73 \pm 4.2 ) were observed in $9.5 \mathrm{~g} / \mathrm{kg}$ treatment category, but it is not significantly different $(\mathrm{P}>0.05)$ from $6.5 \mathrm{~g} / \mathrm{kg}$ treatment group which showed $91.43 \pm 0.9 \%$ males. Fish fed diets fortified with Withania root powder at this concentration showed a high percentage of survival as well (Table 1). The control group showed the highest percentage of females $(65.30 \pm 2.7)$ and it was significantly higher $(\mathrm{P}<0.05)$ than all the treatment categories. The control diet fed group showed no intersex fish while the highest percentage of intersex fish $(7.17 \pm 0.9)$ was observed in tilapia fed diets containing powdered $W$. somnifera roots at the concentration of $2.0 \mathrm{~g} / \mathrm{kg}$ (Table 1). Among the treatment categories, fish fed diets at the concentration of $6.5 \mathrm{~g} / \mathrm{kg}$ showed the lowest percentage $(0.87 \pm 0.9)$ of intersex (Table 1). Though significantly higher than the control group, treatment with Withania root powder at concentration of 2.0, 3.0, 3.5, 5.0 and $7.0 \mathrm{~g} / \mathrm{kg}$ showed low percentage of males, which was not suitable for 
commercial production of monosex tilapia population (Table 1). Dietary administration of Withania root powder at the concentration of $8.0 \mathrm{~g} / \mathrm{kg}$ and $9.5 \mathrm{~g} / \mathrm{kg}$ resulted in high percentage of males. But these two groups showed the highest percentage of mortality as well (Table 1). It might be postulated that the low number of fish left till the end of the experiment for those two groups had resulted in skewness towards a particular sex. Considering the results, dietary treatment with $W$. somnifera root powder at the concentration of $6.5 \mathrm{~g} / \mathrm{kg}$ might be regarded as the best treatment regime for commercial production of monosex tilapia population.

$W$. somnifera roots have been reported to show the presence of phytoconstituents such as tannins, saponins, terpenoids, steroids and flavonoids [22]. These phytoconstituents might be the cause behind the androgenic activity of the plant. A notable increase in testicular weight and increase in the diameter and cell layers of seminiferous tubules was observed in immature male Wistar rats treated with aqueous extract of $W$. somnifera [23]. Different pathways have been postulated to be linked with the functional mechanisms of these phytochemicals causing both masculinisation and feminization at different concentrations [24]. After treatment of infertile men with Withania somnifera, testosterone levels increased significantly, while prolactin decreased in the serum [25]. This is interesting, because prolactin counteracts the effect of dopamine which is responsible for sexual arousal and motivation [26]. The phytochemicals may either act as aromatase inhibitor to block estrogen synthesis or as nuclear estrogen receptor antagonist in primordial gonadal cells to affect masculinisation in fish [27, 28]. It was also reported that methanol, chloroform and distilled water extracts of Withania somnifera root revealed the maximum presence of phytochemicals [22]. Hence, further analysis is required to find out the effective factors functional behind the androgenic potency of the plant.

\section{Conclusion}

The results emanating from this study indicate that the plant might be used as an alternative method to produce all-male tilapia population in an environment-friendly manner using a natural product. However, the highest percentage of males produced by the plant material was found to be well below the ideal requirement of $100 \%$ male population. Thus, further studies are required to establish an ideal treatment regime for production of all-male tilapia population using the plant material and to provide conclusive evidence regarding its efficacy to be used as a sex-reversal agent in tilapia culture.

Table 1: Percentage of survival, male, female and intersex during dietary treatment with Withania somnifera root powder at different concentrations. Different superscripts mark significant differences $(\mathrm{P}<0.05)$ in means within columns.

\begin{tabular}{|l|l|l|l|l|}
\hline Treatment category & Survival $(\%)$ & Male $(\%)$ & Female $(\%)$ & Intersex $(\%)$ \\
\hline Control & $98.33 \pm 0.8^{\mathrm{a}}$ & $34.70 \pm 2.7^{\mathrm{c}}$ & $65.30 \pm 2.7^{\mathrm{a}}$ & $0.0 \pm 0.0^{\mathrm{a}}$ \\
\hline $2.0 \mathrm{~g} / \mathrm{kg}$ & $93.33 \pm 0.8^{\mathrm{a}}$ & $60.73 \pm 0.7^{\mathrm{b}}$ & $32.10 \pm 1.3^{\mathrm{b}}$ & $7.17 \pm 0.9^{\mathrm{a}}$ \\
\hline $3.0 \mathrm{~g} / \mathrm{kg}$ & $93.33 \pm 1.7^{\mathrm{a}}$ & $57.13 \pm 1.6^{\mathrm{b}}$ & $39.37 \pm 2.9^{\mathrm{b}}$ & $3.50 \pm 3.5^{\mathrm{a}}$ \\
\hline $3.5 \mathrm{~g} / \mathrm{kg}$ & $95.00 \pm 2.5^{\mathrm{a}}$ & $59.60 \pm 0.9^{\mathrm{b}}$ & $35.97 \pm 0.07^{\mathrm{b}}$ & $4.43 \pm 0.9^{\mathrm{a}}$ \\
\hline $5.0 \mathrm{~g} / \mathrm{kg}$ & $99.17 \pm 0.8^{\mathrm{a}}$ & $60.53 \pm 2.8^{\mathrm{b}}$ & $38.60 \pm 3.4^{\mathrm{b}}$ & $0.87 \pm 0.9^{\mathrm{a}}$ \\
\hline $6.5 \mathrm{~g} / \mathrm{kg}$ & $97.50 \pm 1.4^{\mathrm{a}}$ & $91.43 \pm 0.9^{\mathrm{a}}$ & $7.70 \pm 1.5^{\mathrm{c}}$ & $0.87 \pm 0.9^{\mathrm{a}}$ \\
\hline $7.0 \mathrm{~g} / \mathrm{kg}$ & $92.50 \pm 1.4^{\mathrm{a}}$ & $63.93 \pm 1.4^{\mathrm{b}}$ & $31.50 \pm 2.2^{\mathrm{b}}$ & $4.57 \pm 2.3^{\mathrm{a}}$ \\
\hline $8.0 \mathrm{~g} / \mathrm{kg}$ & $56.67 \pm 3.6^{\mathrm{b}}$ & $91.43 \pm 2.0^{\mathrm{a}}$ & $7.23 \pm 1.1^{\mathrm{c}}$ & $1.33 \pm 1.3^{\mathrm{a}}$ \\
\hline $9.5 \mathrm{~g} / \mathrm{kg}$ & $56.67 \pm 3.0^{\mathrm{b}}$ & $93.73 \pm 4.2^{\mathrm{a}}$ & $4.67 \pm 2.7^{\mathrm{c}}$ & $1.60 \pm 1.6^{\mathrm{a}}$ \\
\hline
\end{tabular}

\section{Acknowledgements}

The research is financed by the Department of Science and Technology, Government of West Bengal (No 1047/ST/P/S\&T/2G-3/2015). The Vice Chancellor, University of Calcutta is also acknowledged for giving permission for conducting the research work.

\section{References}

[1]. Y.H. Lin, S.M. Lin and S.M. Shiau. Dietary Manganese Requirements of Juvenile Tilapia, Oreochromis niloticus x O. aureus. Aquaculture, 284, 2008, 207-210.

[2]. M.M.N. Authman, M.A. El-Kasheif and K.A.S. Shallof. Evaluation and Management of the Fisheries of Tilapia species in Damietta Branch of the River Nile, Egypt. World J. Fish and Marine Sci., 1(3), 2009, 167-184.

[3]. S.C. Mandal, M. Hasan, M.S. Rahman, M.H. Manik, Z.H. Mahmud and M.D.S. Islam. Coliform bacteria in Nile Tilapia, Oreochromis niloticus of shrim p-Gher, pond and fish market. World J. Fish and Marine Sci., 1(3), 2009, 160-166.

[4]. S. Palipoch, W. Jiraungkoorskul, T. Tansatit, N. Preyavichyapugdee, W. Jaikua and P. Kosai. Effect of Thunbergia laurifolia (Linn) leaf extract dietary supplement against lead toxicity in Nile Tilapia (Oreochromis niloticus). World J. Fish and Marine Sci., 3(1), 2011, 01-09.

[5]. F.A. Chapman. Culture of Hybrid Tilapia: A Reference Profile, Department of Fisheries and Aquatic Sciences, Florida Cooperative Extension Service, Institute of Food and Agricultural Sciences, University of Florida. Circular 1051, 1992.

[6]. R.D. Guerrero III and L. A. Guerrero. Feasibility of commercial production of Nile tilapia fingerlings in Philippines: In RSV Pullin, T Bhukaswan, K Tonguthai, JL Maclean, eds. The Second International Symposium on Tilapia in Aquaculture. ICLARM Conference Proceedings 15, Department of Fisheries, Bangkok, Thailand, and International Center for Living Aquatic Resources Management, Manila, Philippines, 1988, 183-186. 
[7]. G.C. Mair. The problem of sexual maturity in tilapia culture. In: G. C. Mair and T. A. Abella (eds.). Technoguide on the Production of Genetically Male Tilapia (GMT), Freshwater Aquaculture Center, Central Luzon State University, Nueva Ecija, Philippines. 67 p, 1997; pp. 6-13.

[8]. K.V. Thomas, M.R. Hurst, P. Matthiessen, M. Mchugh, A. Smith and M.J. Waldock. An assessment of in vitro androgenic activity and the identification of environmental androgens in United Kingdom estuaries. Environmental Toxicology and Chemistry 21, 2002, 1456-1461.

[9]. D.M Papoulias, D.B Noltie and D.E. Tillitt. Effects of methyl-testosterone exposure on sexual differentiation in medaka, Oryzias latipes. Marine Environmental Research, 50, 2000, 181-184.

[10]. T. Citarasu. Herbal biomedicines: a new opportunity for aquaculture industry. Aquacult. Int., 18, $2010,403-414$.

[11]. S.B. Chakraborty and C. Hancz, Application of phytochemicals as immunostimulant, antipathogenic and antistress agents in finfish culture. Rev. Aquaculture., 3, 2011, 103-119.

[12]. E.T. Eng, D. William, U. Mandava, U. Kirma, R.R. Tekmal and S. Chen. Suppression of aromatase (estrogen synthetase) by red wine phytochemicals. Breast Cancer Research and Treatment, 67, 2001, 133-146.

[13]. M.A Rempel and D. Schlenk. Effects of environmental estrogens and antiandrogens on endocrine function, gene regulation, and health in fish. Int. Rev. Cell Mol. Biol., 267, 2008, 207-252.

[14]. G. Rodriguez, L. Frantz and K. Dabrowski. Use of dietary phytochemicals as a new method to sex-reverse nile tilapia - aqueous plant extracts versus synthetic steroids; The Ohio State University, School of Environment and Natural Resources, Columbus OH 43210 USA, 2005

[15]. S. Imtiyaz, S. Javed Ali, M. Aslam, M. Tariq and S.S. Chaudhary. Withania somnifera: a potent unani aphrodisiac drug. Int. Res J Pharm. App Sci., 3(4), 2013, 59-63.

[16]. M. Kabeeruddin and M. Mufradat. 2nd ed, Idara kitabul shifa, New Delhi, 2010, 75-6.

[17]. N. Nagashyana, P. Sankarankutty, M.R.V. Nampoothiri, P. Moahan and P. Mohan Kumar. Association of L- dopa with recovery following Ayurvedic medication in Parkinson's disease. J Neurol Sci., 176, 2000, 1121-1127.

[18]. V.R. Ambiye, D. Langade, S. Dongre, P. Aptikar, M. Kulkarni and A. Dongre. Clinical Evaluation of the Spermatogenic Activity of the Root Extract of Ashwagandha (Withania somnifera) in Oligospermic Males: A Pilot Study. Evid Based Complement Alternat Med., 2013, 2013,571420.

[19]. R.D. Guerrero and W.L. Shelton. An aceto-carmine squash method for sexing juvenile fishes. Prog. Fish-Cult, 36, $1974,56$.

[20]. A. Rekha, B. Bharathi and S. Ramesh. Effect of some medicinal herbal extracts on clinically important bacterial pathogens. International Journal of Pharmaceutical Sciences and Research 2(9), 2011, 2362-2367.

[21]. M.O. Bello, O.S. Falade, S.R.A. Adewusi and N.O. Olawore. Studies on the chemical compositions and anti nutrients of some lesser known Nigeria fruits. African Journal of Biotechnology, 7, 2008, 3972-3979.

[22]. C. Saidulu, C. Venkateshwar and S. Gangadhar Rao. Preliminary Phytochemical Studies of Medicinal Plant Drug: Withania somnifera Linn. Biolife, 2(1), 2014, 306-312.

[23]. E.M. Abdel Magied, H.A. Abdel - Rahman and F.M. Harraz. The effect of aqueous extracts of Cynomorium coccineum and Withania somnifera on testicular development in immature Wistar rats, J Ethnopharmacol, 75(1), 2001, 1-4.

[24]. S.B. Chakraborty, P. Horn and C. Hancz. Application of phytochemicals as growth-promoters and endocrine modulators in fish culture. Reviews in Aquaculture, 6, 2014, 1-19.

[25]. M.K. Ahmad, A.A. Mahdi, K.K. Shukla, N. Islam, S. Rajender, D. Madhukar, S.N. Shankhwar and S. Ahmad. Withania somnifera improves semen quality by regulating reproductive hormone levels and oxidative stress in seminal plasma of infertile males. Fertil Steril., 94(3), 2010, 989-96.

[26]. T.H. Krüger, U. Hartmann and M. Schedlowski. Prolactinergic and dopaminergic mechanisms underlying sexual arousal and orgasm in humans. World Journal of Urology, 23(2), 2005, 130-138.

[27]. E.T. Eng, D. William, U. Mandava, U. Kirma, R.R. Tekmal and S. Chen. Suppression of aromatase (estrogen synthetase) by red wine phytochemicals. Breast Cancer Research and Treatment, 67, 2001, 133-146.

[28]. M.A. Rempel and D. Schlenk. Effects of environmental estrogens and antiandrogens on endocrine function, gene regulation, and health in fish. Int. Rev. Cell Mol. Biol., 267, 2008, 207-252. 